\title{
White matter magnetic resonance hyperintensities in dementia of the Alzheimer type: morphological and regional cerebral blood flow correlates
}

\author{
Gunhild Waldemar, Pernille Christiansen, Henrik B W Larsson, Peter Høgh, \\ Henning Laursen, Niels A Lassen, Olaf B Paulson
}

\begin{abstract}
In a prospective MRI study the presence, appearance, volume, and regional cerebral blood flow (rCBF) correlates of periventricular hyperintensities (PVHs) and deep white matter hyperintensities (DWMHs) were examined in 18 patients with probable Alzheimer's disease and in 10 age matched healthy control subjects, all without major cerebrovascular risk factors. The ${ }^{133} \mathrm{Xe}$ inhalation method and the [ $\left.{ }^{99 \mathrm{~m}} \mathrm{Tc}\right]-d, l$-hexamethyl-propyleneamine-oxime (HMPAO) technique with single photon emission computed tomography (SPECT) were used to measure rCBF. Rating scores for PVHs were significantly higher in the Alzheimer's disease group $(p<0.01)$ and correlated significantly with the volume of ventricles $(p<0.05)$ and with systolic arterial blood pressure $(p<0.01)$, but not with rCBF. By contrast, there was no significant difference in the rating scores or volumes of DWMHs between the two groups, although three patients had extensive DWMH lesions in the central white matter. In the group of patients with Alzheimer's disease as a whole, the volume of DWMHs correlated well with rCBF in the hippocampal region $(r=$ -0.72 ; $p<0.001$ ), but not with frontal, temporal, parietal, or occipital rCBF. Postmortem histopathology of extensive DWMH lesions in one patient with definite Alzheimer's disease showed a partial loss of myelin and astrocytic gliosis, but no ischaemic changes. It is concluded that DWMH lesions may be associated with reduced $\mathrm{rCBF}$ in the hippocampal region. The heterogenous topography of neocortical rCBF deficits in Alzheimer's disease could not be explained by deafferentation from underlying white matter hyperintensities and therefore may reflect variations in the topography of cortical abnormalities.
\end{abstract}

$(\Im$ Neurol Neurosurg Psychiatry 1994;57:1458-1465)

Although the hallmarks of Alzheimer's disease are the plaques and tangles seen in cortical brain tissue on neuropathological examination, Alzheimer's disease is not just a cortical brain disease. Structural involvement of the white matter was suggested in a neuropathological study by Brun and Englund, ${ }^{1}$ who showed symmetric deep ischaemic white mat- ter changes in most of their patients with a definite diagnosis of Alzheimer's disease. Clinical studies measuring the occurrence of white matter abnormalities on MRI in patients with Alzheimer's disease, however, have yielded conflicting results. ${ }^{2-7}$

Recently, we described a pronounced topographical heterogeneity of regional cerebral blood flow (rCBF) patterns measured with high resolution single photon emission computed tomography (SPECT) and [ $\left.{ }^{99 \mathrm{~m}} \mathrm{Tc}\right]-$ $d, l$-hexamethyl-propylene-amine-oxime (HMPAO) in patients with a clinical diagnosis of Alzheimer's disease.$^{8} \mathrm{~A}$ heterogeneity of hypometabolism patterns in Alzheimer's disease was also reported in PET studies. ${ }^{910}$ In the absence of vascular pathology, focal deficits in cortical blood flow may reflect either abnormalities in the cortex itself or deafferentation from the underlying white matter. The possible contributions of white matter hyperintensities seen on MRI to the pathogenesis of Alzheimer's disease and to the heterogenous impairments of cognitive function and rCBF remain to be clarified. Also, it is not known whether white matter hyperintensities seen on MRI during the course of the disease have any relation with the histopathological white matter disorder described in neuropathological studies. ${ }^{1}$

The aim of this study was to examine the correlation of MRI white matter hyperintensities with $\mathrm{CCBF}$ as measured with SPECT and [ ${ }^{99 \mathrm{~m} T c]-d, l-H M P A O}$. In particular, we aimed to investigate the hypothesis that the presence, topography, or severity of white matter hyperintensities could contribute to the rCBF reduction in the hippocampal regions or to the topographical heterogeneity of $\mathrm{rCBF}$ deficits in neocortical brain regions. This report also includes the postmortem neuropathological study in one patient with $\mathrm{Alz}$ heimer's disease and with extensive deep white matter hyperintensities on MRI.

Patients and methods

PATIENTS

This prospective study comprised 18 right handed patients who were consecutively referred to the dementia clinic for diagnosis. They fulfilled the DSM-IIIR ${ }^{11}$ criteria for dementia and the National Institute of Neurological Disorder and Stroke and the Alzheimer Disease and Related Disease Association (NINCDS-ADRDA) ${ }^{12}$ criteria for probable Alzheimer's disease (table 1). The patients were part of a prospective dementia 
Table 1 Clinical characteristics and MRI data

\begin{tabular}{|c|c|c|c|}
\hline & Control & Alzheimer's disease & \\
\hline \multicolumn{4}{|l|}{ Clinical data: } \\
\hline No of subjects (female/male) & $10(4 / 6)$ & $18(11 / 7)$ & \\
\hline Age & $64(53-80)$ & $69(53-78)$ & NS \\
\hline Duration of symptoms (y) & - & $4(0 \cdot 5-10)$ & \\
\hline $\mathrm{MMSE}^{14}$ score $(\max 30)$ & $30(28-30)$ & $17(3-27)$ & $\star \star$ \\
\hline $\mathrm{GDS}^{15}$ score $(\max 7)$ & - & $4(3-6 d)$ & \\
\hline \multicolumn{4}{|l|}{ Resting arterial blood pressure: } \\
\hline Systolic & $130(110-160)$ & $140(95-165)$ & NS \\
\hline Diastolic & $85(70-90)$ & $78(60-95)$ & NS \\
\hline \multicolumn{4}{|l|}{ MRI data: } \\
\hline PVH score & $0.0(0-1)$ & $1 \cdot 5(0-3)$ & $\star \star$ \\
\hline DWMH score & $1 \cdot 0(0-1)$ & $1.0(0-3)$ & NS \\
\hline $\begin{array}{l}\text { Total volume of DWMH }\left(\mathrm{cm}^{3}\right) \\
\text { (mean (SD)) }\end{array}$ & $\begin{array}{l}0.07(0-4.96) \\
(0.79(1.55))\end{array}$ & $\begin{array}{l}1.04(0-47 \cdot 6) \\
(5 \cdot 39(11 \cdot 3))\end{array}$ & NS \\
\hline $\begin{array}{l}\text { Total volume of ventricles }\left(\mathrm{cm}^{3}\right) \\
\text { (mean (SD)) }\end{array}$ & $\begin{array}{l}24 \cdot 5(8 \cdot 9-56 \cdot 2) \\
(31 \cdot 1(17 \cdot 8))\end{array}$ & $\begin{array}{l}46 \cdot 9(18 \cdot 6-127 \cdot 2) \\
(54 \cdot 2(33 \cdot 1))\end{array}$ & NS \\
\hline
\end{tabular}

Values are median (range) unless stated otherwise. Control $=$ healthy control subjects Alzheimer's disease = patients with a clinical diagnosis of probable Alzheimer's disease; MMSE = Alzheimer's disease $=$ patients with a clinical diagnosis of probable Alzheimer's disease; $M$ MSE $=$
mini mental state examination $14 ;$ GDS = global deterioration scale s. $^{15}$ PVH = periventricular mini mental state examination ${ }^{14}$; GDS $=$ global deterioration scale $^{15} ;{ }_{\star \star} \mathrm{PVH}=$ periventricular
hyperintensities; DWMH $=$ deep white matter hyperintensities. significant (patients with Alzheimer's disease $v$ control subjects, Wilcoxon two sample rank sum test).

study reported elsewhere ${ }^{8}$ and the present report includes only patients in whom a cranial MRI study was available. In one patient (case 04-19), the diagnosis was later confirmed by postmortem neuropathological examination. All patients underwent an extensive study programme to rule out any other disorders that might be associated with dementia, cognitive dysfunction, or altered rCBF. ${ }^{8}$ Briefly, cranial $x$ ray CT was without focal pathology and without periventricular hypodensity in all patients: No patient had a history of psychiatric or neurological disease, except for Alzheimer's disease. All patients had Hamilton ${ }^{13}$ depression scores below or at 10 . Cerebrovascular risk factors were minimised: patients with diabetes mellitus, moderate to severe impairment of cardiac or pulmonary function, significant stenosis of the carotid arteries on Doppler examination, chronic arterial hypertension, or increased cholesterol concentrations in the blood were excluded. Resting systolic/diastolic blood pressure was below $180 / 100$ on the study day. The severity of dementia was documented (table 1) by the mini mental state examination (MMSE) $)^{14}$ and the global deterioration scale (GDS) ${ }^{15}$
Ten age matched healthy volunteers, recruited from advertisements, served as a control group for the MRI data (table 1). They had no dementia symptoms or signs, and they met the same exclusion criteria as the patients with Alzheimer's disease. The mapping of significant $\mathrm{rCBF}$ deficits in the patients with Alzheimer's disease was based on the rCBF data from a larger control group with 25 healthy control subjects, median age 70 (range 53-83) years. ${ }^{8}$ The patients, with their relatives, and all control subjects gave informed consent to participation in the study, which was approved by the ethics committee of the Cities of Copenhagen and Frederiksberg.

\section{MAGNETIC RESONANCE IMAGING}

The MRI study was carried out with a whole body MR scanner (Siemens Magnetom H-15) operating at $1.5 \mathrm{~T}$. The brain was imaged in the axial plane using a double spin echo sequence with repetition time of $1800 \mathrm{~ms}$ and an echo time of $30 / 90 \mathrm{~ms}$. The slice thickness was $4 \mathrm{~mm}$, and the number of slices was 15 with an interslice space of $4 \mathrm{~mm}$. The matrix size was $256 \times 256$ giving a voxel size of $1.2 \times 1.2 \times 4 \mathrm{~mm}^{3}$. The interslice spaces left were also imaged.

The images were analysed by two experienced readers of MRI who were not acquainted with the diagnosis of the patients or the rCBF data. Firstly, the readers were asked to rate (in consensus) the presence, shape, and severity of any periventricular hyperintensities (PVHs) and deep white matter hyperintensities (DWMHs) according to a qualitative scoring method based on the ratings defined by Fazekas et $a l^{2}$ and Zimmermann et al. ${ }^{16}$ The PVHs were rated on a $0-4$ scale $(0=$ absent; $1=$ discontinuous PVH; 2 = continuous periventricular lining; 3 $=$ continuous periventricular halo; $4=$ continuous irregular PVHs). Discontinuous PVHs were defined as rounded hyperintense foci at the angles of the frontal horns, caps of hyperintensity surrounding the occipital horns, and

Table 2 Magnetic resonance hyperintensities and rCBF deficits in patients with probable Alzheimer's disease

\begin{tabular}{|c|c|c|c|c|c|c|c|c|}
\hline \multirow{3}{*}{ Case } & \multirow{3}{*}{$\begin{array}{l}\text { PVH } \\
\text { score }\end{array}$} & \multirow{3}{*}{$\begin{array}{l}D W M H \\
\text { score }\end{array}$} & \multicolumn{4}{|c|}{$D W M H$ volume $\left(\mathrm{cm}^{3}\right)$} & \multirow{2}{*}{\multicolumn{2}{|c|}{ Cortical $r C B F$ deficits }} \\
\hline & & & & Central & Left lobar & Right lobar & & \\
\hline & & & Total & & white matter & white matter & Left & Right \\
\hline $01-02$ & 2 & 0 & 0 & 0 & 0 & 0 & $\mathrm{~T}, \mathbf{P}$ & $\mathrm{F}, \mathrm{T}, \mathrm{P}$ \\
\hline $02-09$ & 0 & 1 & $2 \cdot 08$ & $2 \cdot 08$ & 0 & 0 & 1 & \\
\hline 03-17 & 2 & 1 & 0.68 & 0.68 & 0 & 0 & $\mathrm{~F}, \mathrm{~T}$ & $\mathrm{~F}$ \\
\hline $04-19$ & 1 & 2 & $15 \cdot 20$ & $15 \cdot 20$ & 0 & 0 & $\mathrm{~T}$ & $\mathrm{~F}, \mathrm{~T}, \mathrm{P}, \mathrm{OC}$ \\
\hline $05-21$ & 1 & 1 & 10.04 & $9 \cdot 24$ & $0.48(\mathrm{~F}+\mathrm{OC})$ & $0 \cdot 32(\mathrm{~F})$ & - & $\mathbf{F}, \mathrm{T}$ \\
\hline $06-23$ & 1 & 1 & $4 \cdot 52$ & $4 \cdot 40$ & 0 & $0.12(\mathrm{P})$ & $\mathrm{T}, \mathrm{P}, \mathrm{OC}$ & $\mathrm{T}, \mathrm{P}$ \\
\hline $07-26$ & 1 & 1 & 3.50 & 3.48 & $0.02(\mathrm{OC})$ & 0 & $F, P$ & $\mathrm{~F}$ \\
\hline $08-32$ & 0 & 0 & 0 & 0 & 0 & 0 & $\mathrm{~F}, \mathrm{~T}, \mathrm{P}, \mathrm{OC}$ & - \\
\hline $09-33$ & 2 & 1 & $4 \cdot 52$ & 1.96 & $1.40(\mathrm{OC})$ & $1 \cdot 16(\mathrm{OC})$ & $\mathrm{T}$ & $\mathrm{F}, \mathrm{T}$ \\
\hline $10-34$ & 0 & 1 & 0.92 & 0.56 & 0.28 (OC) & $0.08(\mathrm{OC})$ & $\mathbf{F}$ & - \\
\hline $11-37$ & 2 & 1 & $0 \cdot 10$ & $0 \cdot 10$ & 0 & 0 & F, T, P & $\mathrm{F}$ \\
\hline $12-41$ & 3 & 3 & $47 \cdot 62$ & $47 \cdot 62$ & 0 & 0 & $\mathrm{~F}, \mathrm{~T}, \mathrm{P}$ & - \\
\hline $13-43$ & 2 & 1 & 0.64 & 0.64 & 0 & 0 & - & $\mathrm{T}, \mathrm{P}$ \\
\hline $14-44$ & 3 & 1 & $1 \cdot 16$ & $1 \cdot 16$ & 0 & 0 & - & $\mathrm{OC}$ \\
\hline $15-47$ & 2 & 1 & 0.44 & $0 \cdot 28$ & 0 & $0 \cdot 16(\mathrm{~F})$ & - & $\mathbf{P}$ \\
\hline $16-51$ & 1 & 1 & $5 \cdot 12$ & $5 \cdot 12$ & 0 & 0 & $\mathrm{~T}, \mathbf{P}$ & - \\
\hline $17-52$ & 2 & 2 & 0.40 & 0.40 & 0 & 0 & $\mathrm{~T}, \mathrm{P}$ & $\mathrm{F}, \mathrm{T}, \mathrm{P}$ \\
\hline $18-53$ & 0 & 0 & 0 & 0 & 0 & 0 & $T$ & $\mathrm{~F}, \mathrm{~T}, \mathrm{P}$ \\
\hline
\end{tabular}

rCBF = Regional cerebral blood flow; $\mathrm{PVH}=$ periventricular hyperintensities; $\mathrm{DWMH}=$ deep white matter hyperintensities;

$\mathrm{F}=$ frontal cortex $\mathrm{T}=$ temporal cortex; $\mathrm{P}=$ parietal cortex; $\mathrm{OC}=$ occipital cortex. 
Table 3 Correlation coefficients for white matter magnetic resonance hyperintensities $\mathrm{v}$ clinical data and rCBF in patients with probable Alzheimer's disease $(n=18)$

\begin{tabular}{|c|c|c|c|}
\hline & PVH score & $D W M H$ score & $D W M H$ volume \\
\hline Age & $0 \cdot 46$ & $0.52 \dagger$ & $0 \cdot 29$ \\
\hline Age at onset & 0.45 & 0.44 & $0 \cdot 30$ \\
\hline Duration of symptoms & -0.07 & $-0 \cdot 22$ & $0 \cdot 23$ \\
\hline \multicolumn{4}{|c|}{ Resting arterial blood pressure: } \\
\hline Systolic & $0.76+t$ & $0.48 \dagger$ & $0 \cdot 23$ \\
\hline Diastolic & 0.47 & 0.46 & $0 \cdot 28$ \\
\hline \multicolumn{4}{|l|}{ MRI data: } \\
\hline PVH score & NR & $0.51 \dagger$ & 0.44 \\
\hline DWMH score & $0.51 \dagger$ & NR & $0 \cdot 76^{\star \star \star}$ \\
\hline DWMH volume & $0 \cdot 11$ & $-0.76+t$ & NR \\
\hline Volume of ventricles & $0.52 \dagger$ & 0.38 & $0 \cdot 47^{\star}$ \\
\hline MMSE score & $-0 \cdot 17$ & $0 \cdot 25$ & $0 \cdot 20$ \\
\hline \multicolumn{4}{|l|}{ Cerebral blood flow $(a / b)$ : } \\
\hline $\begin{array}{l}\text { Global CBF } \\
\text { rCBF }\end{array}$ & $-0.34 /-0.35$ & $-0 \cdot 29 /-0 \cdot 14$ & $-0 \cdot 52 /-0 \cdot 24$ \\
\hline Frontal cortex & $-0.38 /-0.36$ & $-0.31 /-0.10$ & $-0.42 /-0.30$ \\
\hline Temporal cortex & $-0.29 /-0.27$ & $-0.26 /-0.09$ & $-0.46 /-0.18$ \\
\hline Parietal cortex & $-0 \cdot 32 /-0.24$ & $-0.24 /-0.06$ & $-0.27 /-0.24$ \\
\hline Occipital cortex & $-0.41 /-0.34$ & $-0.32 /-0 \cdot 14$ & $-0.30 /-0.26$ \\
\hline Hippocampal region & $-0 \cdot 15 / \mathrm{NA}$ & $-0 \cdot 22 / \mathrm{NA}$ & $-0 \cdot 72^{\star \star \star} / \mathrm{NA}$ \\
\hline Central white matter & $-0.42 / \mathrm{NA}$ & $-0.28 / \mathrm{NA}$ & $-0.56^{\star} / \mathrm{NA}$ \\
\hline
\end{tabular}

${ }^{\star} \mathrm{p}<0.05 ;{ }^{\star \star \star} \mathrm{p}<0.001$ (Pearson product-moment correlations).

tp $<0.05 ;$ ttp $<0.01$ (Spearman rank order correlations).

$\mathrm{a} / \mathrm{b}=$ correlation coefficients; these are shown for $\mathrm{rCBF}$ data obtained with both CBF methods $\left(\left[{ }^{99 \mathrm{~m}} \mathrm{Tc}\right]-d, l\right.$-HMPAO $(a) /{ }^{133} \mathrm{Xe}$ inhalation $\left.(b)\right) ; \mathrm{PVH}=$ periventricular white matter hyperintensities; DWMH = deep white matter hyperintensities; MMSE = mini mental state examination score $\mathrm{NA}=$ not available; $\mathrm{NR}=$ not relevant.

streaks of hyperintensity extending along the atria of the lateral ventricles. Continuous irregular PVHs were defined as PVHs extending from the ventricular lining into the deep white matter to the corticomedullary junction involving most of the white matter, the lateral margins of the hyperintensity being irregular. Separate white matter signal hyperintensities that were not confluent with the ventricular lining were rated as DWMHs on a $0-3$ scale $((0=$ absent $): 1=$ punctuate (solitary) foci; $2=$ beginning of confluence of foci; $3=$ large confluent areas). Next, the readers measured the volume of all DWMH elements in: (a) the central white matter in the frontal and occipital regions and parallel to the lateral ventricles, including all white matter tissue within the corticomedullary junction; (b) lobar white matter separately in the left and right frontal, temporal, parietal, and occipital regions. These regions were defined on templates constructed before the study with reference to axial brain slices from an anatomical brain atlas. ${ }^{17}$ Each hyperintensity lesion was encircled with a cursor on the computer screen, and the area was calculated automatically. The slice volume of each lesion was estimated by multiplying by the voxel volume. The total volume of the hyperintensities was calculated by adding together the volume of all lesions on all slices. The total volume of the ventricles was measured by a similar procedure.

\section{SINGLE PHOTON EMISSION COMPUTED}

TOMOGRAPHY

Firstly, rCBF was measured by the ${ }^{133} \mathrm{Xe}$ inhalation technique with a Tomomatic 64 (Medimatic, Hellerup, Denmark), a rapidly rotating and highly sensitive brain dedicated three slice instrument for brain SPECT described elsewhere. ${ }^{18}$ The ${ }^{133} \mathrm{Xe}$ inhalation study was performed to obtain absolute measures for CBF. From this study global CBF and $\mathrm{rCBF}$ in the cerebellum and in the frontal, temporal, parietal, and occipital cortex were calculated. Methods for calculation of $\mathrm{CBF}$ and regional data analysis have been described elsewhere. ${ }^{18-20}$ Subsequently, rCBF was measured semiquantitatively by static imaging of the distribution of an intravenous dose $(1 \cdot 1 \mathrm{GBq})$ of $\left[{ }^{99 \mathrm{~m}} \mathrm{Tc}\right]-d, l$-HMPAO (Exametazime, Ceretec, Amersham, London, UK). The imaging protocol and the analysis of $\mathrm{rCBF}$ data have been described elsewhere. ${ }^{820}$ Briefly, the count rates from nine contiguous image slices covering the whole brain were corrected to adjust for the initial preferential back diffusion of the tracer from high flow regions by the algorithm suggested by Lassen $e t$ $a l,{ }^{21}$ with a conversion to clearance ratio of 1.5. The cerebellar hemisphere with the highest count rate was used as the reference region. Mean $\mathrm{rCBF}$ was calculated in the hippocampal regions and in frontal, temporal, parietal, and occipital cortical regions of interest. ${ }^{82022}$ The side to side asymmetry index was defined as the difference between rCBF values in the right and the left counterparts of the region of interest, relative to the higher of the two values. Two anterior:posterior ratios were defined as the ratio of mean $\mathrm{rCBF}$ in the frontal cortex to mean $\mathrm{rCBF}$ in the temporal cortex or the parietal cortex, respectively. ${ }^{20}$ Based on the rCBF data from a large control group,${ }^{8}$ the regions of interest with significant rCBF deficits were mapped for each patient. In each region of interest $\mathrm{rCBF}$ was considered reduced if the relevant side to side asymmetry index or anterior:posterior ratio of rCBF was significantly abnormal (deviating more than 2 SD from the control mean), or if the mean $\mathrm{rCBF}$ value was severely reduced, by more than $3 \mathrm{SD}$ from the control mean. ${ }^{8}$

\section{CORRELATIONS BETWEEN MRI}

HYPERINTENSITIES, CLINICAL DATA, AND RCBF The rating scores for PVHs and DWMHs and the quantitative volume measurements of DWMHs were compared in the two groups. Within the group of patients with Alzheimer's disease a correlation analysis was carried out for the PVH and DWMH rating scores and for the volume of DWMHs $v$ age, MMSE score, age of disease onset, duration of symptoms, resting systolic and diastolic arterial blood pressure, volume of ventricles, and global as well as rCBF. A correlation analysis was also performed for the side to side asymmetry of the global DWMH volume $v$ that of global CBF. Finally, the MRI variables were compared in the groups of patients with and without frontal hypoperfusion and, when relevant, the rCBF patterns were examined for rCBF deficits in the cortical regions of interest adjacent to any lobar DWMH lesions.

\section{STATISTICAL METHODS}

The Wilcoxon two sample rank sum test was used for intergroup comparisons of data. The possible relations between the quantitative DMWH volume measurements and other variables were analysed by Pearson product moment correlations. Correlations concerning the qualitative rating scores for PVHs and DWMHs were analysed by the Spearman rank order analysis. A Bonferroni correction 
was applied to the $\mathrm{p}$ values for differences in rCBF data. ${ }^{8}$ For all statistical tests the minimal level of significance was $\mathrm{p}<0.05$.

\section{Results}

MAGNETIC RESONANCE IMAGING

The rating scores for PVHs were significantly $(p<0.01)$ higher in the Alzheimer's disease group than in the controls (table 1). By contrast, there was no significant difference in the rating scores or volume measurements of DWMHs between the two groups (table 1). In all control subjects and in most patients
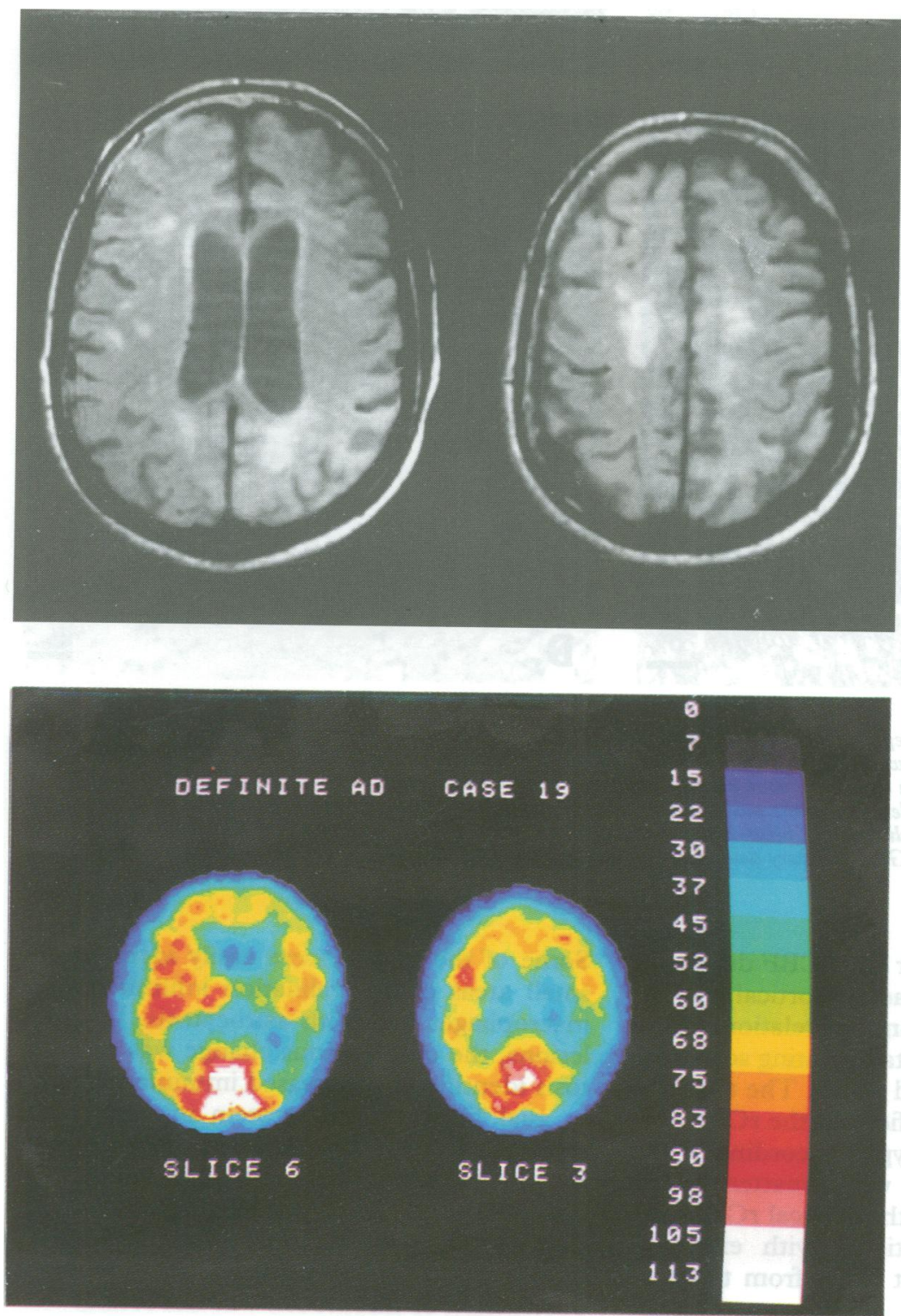

Figure 1 MRI images (top) and $\left.{ }^{99^{m}} T c\right]-d, l-H M P A O$ SPECT images (bottom) from a 72 year old female patient with a diagnosis of definite Alzheimer's disease verified by neuropathological examination at necropsy (case 04-19). The left hemisphere is shown to the left. In the SPECT images the colour scale indicates $r C B F$ (normalised to the cerebellum). This patient presented with presenile onset of progressive dementia, fulfilling the clinical criteria for probable Alzheimer's disease. The MMSE score was 15, and the GDS (global deterioration scale) score was 5. There was no history of cerebrovascular risk factors. In the neuropsychological examination memory, language, visual perception, and visuoconstruction were significantly impaired. On MRI (top) a moderate and diffuse cortical atrophy was seen, the PVH score was 1 , and the DWMH score was 2 . Extensive $D W M H$ lesions, with a total volume of $15 \cdot 2 \mathrm{~cm}^{3}$, were located symmetrically in the central white matter. The SPECT study (bottom) showed asymmetric focal $r C B F$ deficits in the temporoparietal regions and in the right frontal cortex. The symptoms and SPECT

abnormalities continued to progress, still with no clinical signs of vascular brain disorder. Fig 2 shows the postmortem neuropathological examination obtained three years later. with Alzheimer's disease the total volume of DWMHs was below $5 \mathrm{~cm}^{3}$, and more than $95 \%$ of the total DWMH volume was located in the central white matter (tables 1 and 2). In three patients with Alzheimer's disease (cases No 04-19, 05-21, and 12-41), however, the total volume of DWMHs was very high, exceeding by far the maximal DWMH volume in the control group.

\section{SINGLE PROTON EMISSION COMPUTED}

TOMOGRAPHY

Global CBF measured with the $\left.{ }^{99 \mathrm{~m}} \mathrm{Tc}\right]-d, l-$ HMPAO method (normalised to the cerebellum) was 85.2 (SD 7.9 )\% in the control group and $75 \cdot 2(9 \cdot 6) \%$ in the Alzheimer's disease group $(p<0.01)$. There was a significant $(p<0.01)$ reduction of rCBF in the frontal, temporal, and parietal cortexes, and in the hippocampal regions, whereas the occipital cortex and the subcortical grey matter regions were spared. ${ }^{8}$ The individual rCBF patterns have been described elsewhere ${ }^{8}$ and table 2 summarises these. All patients had an abnormal rCBF pattern. A pronounced topographical heterogeneity of $\mathrm{rCBF}$ patterns for the number of affected regions, laterality, and anterior posterior asymmetry, was found. There was no significant difference between the two groups in cerebellar blood flow as measured with the ${ }^{133} \mathrm{Xe}$ inhalation technique.

\section{CORRELATIONS BETWEEN MRI}

\section{HYPERINTENSITIES AND CLINICAL DATA}

Within the group of patients with Alzheimer's disease the DWMH but not the PVH rating scores correlated significantly with age. The PVH scores and the DWMH volumes correlated significantly with the volume of the ventricles (table 3). There was no significant difference in any of the MRI variables between patients with presenile and senile onset of symptoms. The PVH scores correlated significantly with resting systolic arterial blood pressure $(r=0.76 ; \mathrm{p}<0.01)$. Likewise, there was a slight, but significant, correlation between the DMWH scores and systolic arterial blood pressure $(r=0.48 ; \mathrm{p}<0.05)$. None of the MRI variables correlated with age at onset, duration of symptoms, diastolic arterial blood pressure, or cognitive performance as measured with the MMSE score.

\section{CORRELATIONS BETWEEN MRI}

HYPERINTENSITIES AND TCBF

The DWMH volumes correlated significantly with $\mathrm{rCBF}$ in the central white matter $(r=$ $-0.56 ; \mathrm{p}<0.05)$, and remarkably well with $\mathrm{rCBF}$ in the hippocampal region $(r=-0.72 ; \mathrm{p}$ $<0.001$ ), but not with $\mathrm{rCBF}$ in any of the four major cortical regions (table 3). Accordingly, there was no significant correlation between the side to side asymmetry of the DWMH volume and that of cortical rCBF, and there was no significant difference in any of the MRI variables between patients with and without frontal hypoperfusion. Only two of the six patients with small DWMH lesions 

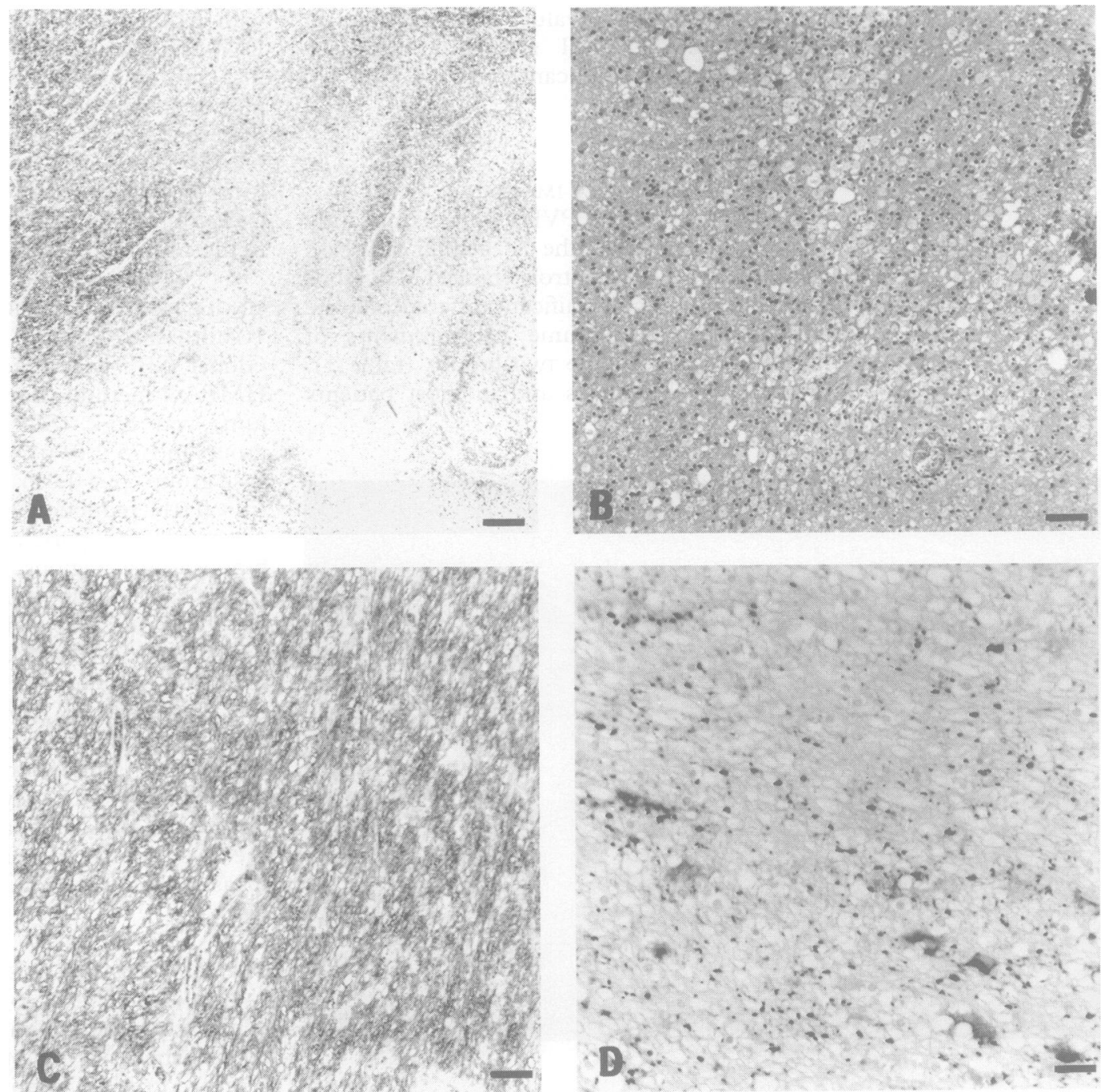

Figure 2 Histological tissue preparations showing white matter lesions in patient 04-19 (for case history see fig 1). (A) Macroscopically identified white matter lesion. Myelin stain shows extensive demyelination. Klüver-Barrera stain (bar $180 \mu \mathrm{m}$ ). (B) Same lesion as in A. Tissue heavily infiltrated by macrophages. Haematoxylin-eosin stain (bar 70 (bar $180 \mu \mathrm{m})$. (B) Same lesion as in A. Tissue heavily infiltrated by macrophages. Haematoxylin-eosin stain (bar 70
$\mu \mathrm{m})$. (C) Macroscopically unidentified white matter lesion. Myelin stain demonstrates pallor and oedematous dispersion of myelinated tracts, but no demyelination. Klüver-Barrera stain (bar $70 \mu m$ ). (D) Same lesion as in C. Astrocytes are swollen with distorted outlines. Glial fibrillary acid protein immunostain (bar $30 \mu \mathrm{m}$ ).

in the lobar white matter had rCBF deficits in one of the relevant adjacent cortical regions (table 2). No significant correlations were found between the qualitative rating scores for PVHs and DWMHs and rCBF. The topography of cortical rCBF deficits in the rCBF patterns could not be subtyped according to the presence or severity of white matter lesions (table 2). In particular, the cortical rCBF patterns of the three patients with extensive DWMH lesions did not differ from those of the other patients.

NEUROPATHOLOGY

In one of the patients (case 04-19) with extensive DWMH lesions a postmortem neuropathological examination was obtained (figs 1 and 2). Abundant plaques and tangles were seen in all cortical brain regions. Only very few of the deep white matter lesions on MRI could be identified macroscopically. Tissue blocks taken from these areas and from periventricular areas with well defined MRI lesions were examined histologically (fig 2).
Some of the lesions were easily identified as small areas of demyelination infiltrated with macrophages and with astrocytosis. In other lesions, the only obvious change was astrocytosis identified by increased immunoreactivity in glial fibrillary acid protein immunohistostains. In some of these lesions a slight pallor in the myelin stain suggested oedematous dispersion of fibre tracts, but obvious demyelination was not present. In all lesions hyalinised blood vessels were present, but complete obstruction or thrombosis was not found.

\section{Discussion}

The highly significant correlation between the volume of DWMHs and hypoperfusion in the hippocampal regions suggested that DWMHs may be a marker for the severity of dysfunction or atrophy in medial temporal lobe structures. This study also showed that white matter hyperintensities could not explain the characteristic topographical heterogeneity of focal cortical rCBF deficits in dementia of the 
Alzheimer type. Therefore, the heterogeneity must reflect variations in the topography of cortical pathology. We used an MRI scoring method that distinguished between PVHs and DWMHs, because histological and epidemiological studies have suggested a different aetiology for these categories of white matter lesions. ${ }^{23} 2324$ The inter-rater reliability of the scoring method has been shown to be very high, ${ }^{5}$ and in our study the qualitative estimation of DWMHs was refined by quantitative volumetric measurements.

The PVH foci just anterior to the frontal horns probably do not reflect pathology. They are thought to be caused by an age related loss of ependyma leading to increased water content. ${ }^{23}$ Thus if a PVH score greater than 1 is abnormal, then abnormal PVHs (continuous PVHs along the side of the ventricles) were seen in $50 \%$ of our patients with Alzheimer's disease but not in any of the healthy subjects. The PVH scores correlated significantly with systolic arterial blood pressure, but differences in blood pressure could not explain the differences in PVHs between the two groups. The low frequency of PVHs in our group of healthy subjects without major cerebrovascular risk factors corresponds to that reported by Fazekas et al. ${ }^{25}$ The increased frequency and extension of PVHs in patients with Alzheimer's disease, which suggested that PVHs may be associated with the Alzheimer's disease process, is in agreement with the findings of McDonald et al. ${ }^{26}$ By contrast, Leys et $a l,{ }^{6}$ Kozachuk et $a l,{ }^{5}$ and Fazekas et $a l^{27}$ failed to find any difference in PVHs between patients with Alzheimer's disease and healthy subjects. Scheltens et $a l^{7}$ found increased severity of PVHs in his group of patients with Alzheimer's disease and with senile onset of disease, but not in presenile onset Alzheimer's disease. We were unable to show any association between the severity of PVHs and age of onset or duration of symptoms. Thus whereas our data on the presence of PVHs in Alzheimer's disease confirmed the results of some, but not all, previous reports, the important finding was that although PVHs were significantly associated with the diagnosis of Alzheimer's disease PVHs were not a determining factor for the cortical rCBF deficits or for global cognitive performance.

By contrast with PVHs the rating scores and volumes of DWMHs were not higher in the group of patients with Alzheimer's disease as a whole. Solitary foci of DWMHs were seen in $70 \%$ of our control subjects, a high frequency that corresponds with that reported by Fazekas et al. ${ }^{25}$ The lack of difference in DWMH scores between patients with Alzheimer's disease and normal subjects was in agreement with the findings of some previous reports, ${ }^{24-628}$ but contradicted others. ${ }^{3}$ 29-33 It is well known that the presence of cerebrovascular risk factors increases the risk of DWMHs, 25,634 and Scheltens $e t a l^{7}$ suggested that DWMHs may be more prevalent in patients with senile onset of Alzheimer's disease than in patients with presenile onset, even when cerebrovascular risk factors have been controlled. In previous studies only subjective rating methods have been applied. By inclusion of volumetric measurements of DWMHs, our study confirmed that when cerebrovascular risk factors have been controlled, the clinical diagnosis of probable Alzheimer's disease is not likely associated with increased DWMHs. Within the group of patients with Alzheimer's disease, however, there was a high variation in the volumetric data, and three patients had extensive DWMH lesions, suggesting a heterogeneity in the presence and severity of DWMHs. A very high variation in DWMH volume measurements was also reported by others. ${ }^{35}$ Furthermore, the highly significant negative correlation with blood flow in the hippocampal regions points to a possible pathophysiological link between DWMHs and the degenerative process of Alzheimer's disease, at least in some patients.

Three questions remain unanswered. Firstly, could DWMHs be part of the Alzheimer's disease process in selected patients? Secondly, if DWMHs on MRI are not associated with Alzheimer's disease, then what are the clinical correlates of the histological white matter lesions that have been described in $60 \%$ of patients with Alzheimer's disease at necropsy? Brun and Englund suggested that these abnormalities were due to hypoperfusion of the concerned white matter territories, but no information from MRI was available in their study. ${ }^{1}$ Thirdly, what are the morphological correlates of the DWMH lesions seen on MRI in healthy subjects as well as in patients with Alzheimer's disease? The literature on histopathological examination of MRI white matter lesions in Alzheimer's disease is sparse: in a preliminary postmortem report on three patients with definite Alzheimer's disease Morris et al ${ }^{36}$ found increased water content, but no histological lesions, in regions with "periventricular high signals". Whether these high signals represented deep white matter hyperintensities or periventricular hyperintensities was not defined in their report, and the vessels were not described. We were able to perform a postmortem neuropathological examination of the brain from one of our patients with definite Alzheimer's disease and extensive DWMH lesions on MRI. The partial loss of myelin and astrocytic gliosis, which was seen in the white matter regions corresponding to those containing DWMHs on MRI, resembled some of the abnormalities described in the necropsy studies by Brun and Englund in patients with Alzheimer's disease. ${ }^{1}$ Similar histopathological changes were found, however, by Fazekas $e t a l^{24}$ in healthy subjects with DWMHs on MRI. In our patient hyalinised blood vessels were found in the central white matter, but they were not associated with vessel occlusion or ischaemic changes. Thus perivascular damage could not be proved to be the substrate of the DWMHs. We suggest that neither the DWMHs on MRI nor the histological white matter findings in our patient were related to the Alzheimer's 
disease process. Most likely DWMHs seen on MRI are related to normal aging, cerebrovascular risk factors, and chronic cerebrovascular disease, ${ }^{37}$ rather than to the Alzheimer's disease process. The prevalent histological white matter disorder described by Brun and Englund $^{1}$ in Alzheimer's disease as well as our finding of a significant correlation between the volume of DWMHs and hypoperfusion in the hippocampal regions, however, support the hypothesis of a pathophysiological link between DWMHs and Alzheimer's disease.

The DWMHs did not contribute to the characteristic cortical rCBF deficits in Alzheimer's disease. The finding was confirmed with the ${ }^{133} \mathrm{Xe}$ inhalation method as well as with the $\left[{ }^{99 \mathrm{~m}} \mathrm{Tc}\right]-d, l$-HMPAO technique for measuring $\mathrm{rCBF}$. In accordance with this, measurements of glucose metabolism with PET have failed to show hypometabolism of cortical areas adjacent to white matter hyperintensities. ${ }^{28}$ Although none of our patients had chronic arterial hypertension, the significant correlation between the severity of PVHs (and to some extent also DWMHs) and systolic arterial blood pressure supports the hypothesis that arterial blood pressure may be an aetiological factor for white matter hyperintensities.

In conclusion, clinically diagnosed Alzheimer's disease without major cerebrovascular risk factors was associated with an increased frequency and severity of PVHs. There was no relation, however, between the presence of PVHs and global cognitive performance or the .rCBF patterns. By contrast, DWMHs were not significantly associated with the diagnosis of Alzheimer's disease. The histopathology of extensive DWMH lesions in one patient with Alzheimer's disease included partial loss of myelin and astrocytosis, changes that were not different from those described in normal subjects with DWMHs. Within the group of patients with Alzheimer's disease, however, the variation in DWMH volumes was high, and the total volume of DWMHs correlated significantly with the reduction of $\mathrm{rCBF}$ in the hippocampal regions, suggesting a pathophysiological link between DWMHs and Alzheimer's disease. The characteristic and heterogeneous topography of focal cortical rCBF deficits in probable Alzheimer's disease could not be explained by deafferentation from white matter hyperintensities and therefore must reflect variations in the topography of cortical abnormalities.

This study was supported by grants from the Danish Medical Research Council, the Lundbeck Foundation, and the Danish Heart Foundation. Dorthe Givard, Glenna Skouboe, Pia Tejmer, and Gerda Thomsen are gratefully thanked for their excellent secretarial and technical assistance.

1 Brun A, Englund E. A white matter disorder in dementia of the Alzheimer type: a pathoanatomical study. Ann Neurol 1986;19:253-62.

2 Fazekas F, Chawluk JB, Alavi A, Hurtig HI, Zimmerman RA. MR signal abnormalities at $1.5 \mathrm{~T}$ in Alzheimer's dementia and normal aging. AfNR Am ff Neuroradiol 1987;8:421-6.

3 Kertesz A, Polk M, Carr T. Cognition and white matter changes on magnetic resonance imaging in dementia. Arch Neurol 1990;47:387-91.

4 Christie JE, Kean DM, Douglas RHB, Engleman HM, Clair DS, Blackburn IM. Magnetic resonance imaging in pre-senile dementia of the Alzheimer type, multiinfarct dementia and Korsakoff's syndrome. Psychol Med infarct dementia and

5 Kozachuk WE, DeCarli C, Schapiro MB, Wagner EE, Rapoport SI, Horwitz B. White matter hyperintensities in dementia of Alzheimer' type and in healthy subjects without cerebrovascular risk factors. A magnetic resonance imaging study. Arch Neurol 1990;47:1306-10.

6 Leys D, Soetaert G, Petit H, Fauquette A, Pruvo J-P, Steinling $M$. Periventricular and white matter magnetic resonance imaging hyperintensities do not differ between Alzheimer's disease and normal aging. Arch Neurol 1990;47:524-7.

7 Scheltens P, Barkhof F, Valk J, et al. White matter lesions on magnetic resonance imaging in clinically diagnosed Alzheimer's disease. Evidence for heterogeneity. Brain 1992;115:735-48.

8 Waldemar G, Bruhn P, Kristensen M, Johnsen A, Paulson OB, Lassen NA. Heterogeneity of neocortical cerebral blood flow deficits in dementia of the Alzheimer type: a [99mTc]-d,l-HMPAO SPECT study. $\mathcal{f}$ Neurol Neurosurg Psychiatry 1994;57:285-95.

9 Haxby JV, Grady CL, Koss E, et al. Heterogenous anterior-posterior metabolic patterns in dementia of the Alzheimer type. Neurology 1988;38:1853-63.

10 Rapoport SI. Positron emission tomography in Alzheimer's disease in relation to disease pathogenesis: a critical review. Cerebrovasc Brain Metab Rev 1991;3: 297-335.

11 American Psychiatric Association. Diagnostic and statistical manual of mental disorders. 3rd ed revised. DSM-III-R. Washington, DC: American Psychiatric Association, Washingt
1987.

12 McKhann G, Drachman D, Folstein M, Katzman R, Price D, Stadlan EM. Clinical diagnosis of Alzheimer's disease: report of the NINCDS-ADRDA Work Group under the auspices of Department of Health and Human Services Task Force on Alzheimer's Disease. Neurology 1984;34:939-44.

13 Hamilton $M$. Development of a rating scale for primary depression illness. British fournal of Social and Clinical Psychology 1967;6:278-96.

14 Folstein MF, Folstein SE, McHugh PR. "Mini-Mental State". A practical method for grading the cognitive state of patients for the clinician. 7 Psychiatr Res 1975;12. 189-98.

15 Reisberg B, Ferris SH, de Leon MJ, Crook T. The global deterioration scale for assessment of primary degenerative dementia. Am f Psychiatry 1982;139:1136-9.

16 Zimmerman RD, Fleming CA, Lee BCP, Saint-Louis LA, Deck MDF. Periventricular hyperintensity as seen by
Derman magnetic resonance: prevalence and significance. AfNR Am 7 Neuroradiol 1986;7:13-20.

17 Eyclesheimer AC, Schoemaker DM. A cross-section anatomy. London: Butterworths, 1970.

18 Stokely EM, Sveinsdottir E, Lassen NA, Rommer P. A single photon dynamic computer assisted tomograph DCAT) for imaging brain function in multiple cross sections. F Comput Assist Tomogr 1980;4:230-40.

19 Celsis P, Goldman T, Henriksen L, Lassen NA. A method for calculating regional cerebral blood flow from emission computed tomography of inert gas concentrations. f Comput Assist Tomogr 1881;5:641-5.

20 Waldemar G, Hasselbalch SG, Andersen AR, et al. [99mTc]- $d, l$-HMPAO and SPECT of the brain in normal [99m. Tc]-d,l-HMPAO and SPECT of the brain in

21 Lassen NA, Andersen AR, Friberg L, Paulson OB. The retention of [ $\left.{ }^{99 \mathrm{~m}} \mathrm{Tc}\right]-d, l$-HMPAO in the human brain after intracarotid bolus injection. A kinetic analysis. after intracarotid bolus injection. A kinet

22 Aquilonius S-M, Eckernäs S- $\AA$. A colour atlas of the human brain. Adapted to computed tomography. Stockholm: Esselte Studium, 1980

23 Sze G, De Armond SJ, Brant-Zawadzki M, Davis RL, Norman D, Newton TH. Foci of MRI signal (pseudo lesions) anterior to the frontal horns: histologic correlations of a normal finding. American fournal of Roentgenology, Radium Therapy, and Nuclear Medicine 1986;147:331-7.

24 Fazekas F, Kleinert R, Offenbacher $\mathrm{H}$, et al. The morphologic correlate of incidental punctate white matter hyperintensities on MR images. AfNR Am $\mathcal{f}$ Neuroradiol 1991;12:915-21.

25 Fazekas F, Schmidt R, Offenbacher $\mathrm{H}$, et al. Prevalence of white matter and periventricular magnetic resonance white matter and periventricular magnetic resonance
hyperintensities in asymptomatic volunteers. foumal of hyperintensities in asympto

26 McDonald WM, Krishnan KRR, Doraiswamy PM, et al. Magnetic resonance findings in patients with early-onset Magnetic resonance findings in patients with early-ons
Alzheimer's disease. Biol Psychiatry 1991;29:799-810.

27 Fazekas F, Schmidt R, Offenbacher H, Chawluk JB, Alavi A. Magnetic resonance imaging hyperintensities in Alzheimer's disease. [letter]. Arch Neurol 1991;48: 468-9.

28 Fazekas F, Alavi A, Chawluk JB, et al. Comparison of CT, $M R$, and PET in Alzheimer' dementia and normal aging. f Nucl Med 1989;30:1607-15.

29 Bondareff W, Raval J, Coletti PM, Hauser DL. Quantitative magnetic resonance imaging and the severity of dementia in Alzheimer's disease. Am $\mathcal{F}$ Psychiatry 1988;145:853-6. 
30 Bondareff W, Raval J, Woo B, Hauser DL, Colletti PM Magnetic resonance imaging and the severity of dementia Magnetic resonance imaging and the severity of dem

31 Johnson KA, Davis KR, Bounanno FS, Brady TJ, Rosen TJ, Growdon JH. Comparison of magnetic resonance and roentgen ray computed tomography in dementia. Arch Neurol 1987;44:1075-80.

32 Besson JAO, Corrigan FM, Foreman EI, Eastwood LM Smith FW, Ashcroft GW. Nuclear magnetic resonance (NMR) II. Imaging in dementia. Br $\mathcal{f}$ Psychiatry 1985 146:31-5.

33 George AE, de Leon MJ, Kalnin A, Rosner L, Goodgold A, Chase N. Leukoencephalopathy in normal and pathologic aging: 2 . MRI of brain lucencies. $A \mathcal{F} N R \mathrm{Am}^{\mathcal{F}}$ Neurobiol 1986;7:567-70.

34 Fazekas F, Niederkorn $\cdot K$, Schmidt $R$, Offenbacher $H$ Horner S, Bertha G, Lechner $\mathrm{H}$. White matter signal abnormalities in normal individuals: Correlation with carotid ultrasonography, cerebral blood flow measurecarotid ultrasonography, cerebral blood flow measurements, and

35 Almkvist O, Wahlund L-O, Andersson-Lundman G, Basun $\mathrm{H}$, Bäckman L. White matter hyperintensity and neuropsychological function in dementia and healthy aging. Arch Neurol 1992;49:626-32.

36 Morris JC, Gado M, Torack RM, McKeel DW Binswanger's disease or artifact: a clinical and pathological study of periventricular white matter changes in Alzheimers' disease. Adv Neurol 1990;51: 47-52.

37 Awad IA, Johnson PC, Spetzler RF, Hodak JA. Incidental subcortical lesions identified on magnetic resonance imaging in the elderly. II. Postmortem pathological imaging in the elderly. II. Postmort

\section{NEUROLOGICAL STAMP}

\section{Dorothea Lynde Dix (1802-87)}

Dorothea Dix came from New England. Here she noticed the horrible conditions in an asylum. Some warders made a small charge for visitors to come and look at the mad and prod them into raving antics. In 1841 she laid before the Massachusetts General Assembly a description of the insane in jails and private institutions. She spent the rest of her life fighting to improve conditions of the insane.

Anton Ashley Cooper, afterwards Lord Shaftesbury, had discovered similar problems in England 10 years earlier while sitting on a Royal Commission to investigate such conditions. The lunatics at Bedlam were long regarded as one of the sights of London.

Miss Dix travelled thousands of miles by stagecoach, steamboat, and on horseback and quietly collected facts, which she recorded in sober restrained prose. She possessed great charm and a commanding voice. With these attributes, facts collected from a comprehensive study of asylums, and a selection of public speakers to sustain protest she harassed officials and influenced legislatures.

In 1843, in the face of her continuing investigation and increasing community agitation, the Massachusetts Legislature passed a Bill providing for adequate hospitalisation of the insane. This was her first triumph. She became an effective lobbyist in many of the States and a national figure. Her work and influence also led to improvement of the conditions of the insane in Great Britain - and also in Italy after an audience with the Pope. She travelled in Europe and crusaded for human rights of patients until her death at the age of 85 .

The centennial of her death, 1987, went largely unnoticed but in 1980 a United States postage stamp had commemorated the first woman who brought the plight of the mentally ill into such prominence (Stanley Gibbons 1818, Scott 1844).

L F HAAS

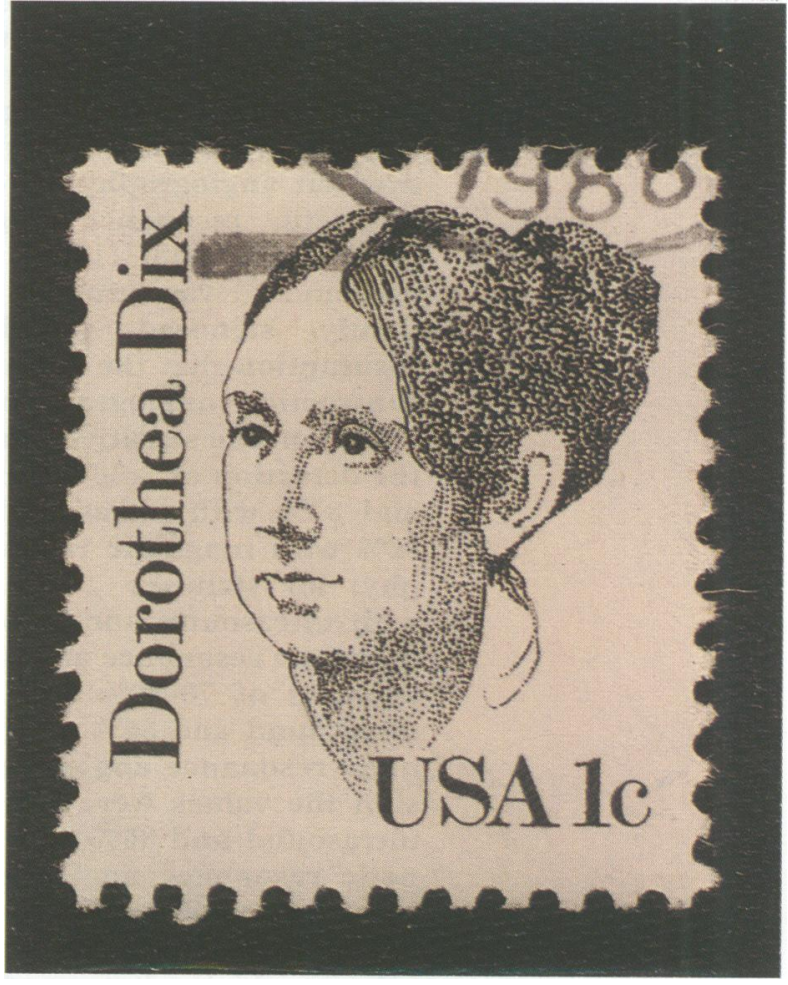

